\title{
Influence of the nanolayer' post-treatment on the anticorrosion activity
}

\author{
J. Telegdi ${ }^{1,2 *}$ and T. Abohalkuma ${ }^{3,4}$ \\ ${ }^{1}$ Óbuda University, Doberdó u. 6., 1034 Budapest, Hungary \\ ${ }^{2}$ Institute of Materials and Environmental Chemistry, Research Centre for Natural \\ Sciences, Hungarian Academy of Sciences, Magyar tudósok körútja 2, 1117 Budapest, \\ Hungary \\ ${ }^{3}$ PhD School of Materials Sciences and Technologies, Óbuda University, Bécsi út 96/B \\ 1016, Budapest, Hungary \\ ${ }^{4}$ Libyan Petroleum Institute, Girgarisg Road Km7, Tripoli, Libya \\ *E-mail: telegdi.judit@ttk.mta.hu
}

\begin{abstract}
The study of self-assembled molecular layer (SAM) of undecenyl phosphonic acid amphiphilic molecule was in the focus of experiments. This molecule has a double bond at the end of the hydrophobic carbon chain, which does not allow the formation of a very compact SAM layer. The nanolayers were developed on carbon steel surface polished before layer deposition. To increase the compactness of the nanolayer, post-treatments were applied. In one case UV light, in the other case gamma-ray irradiation were used to polymerize the double bonds and form a film with net-like structure on the metal surface. The influence of the SAM layer treatments on the layer structure was followed by monitoring the change in water wettability and by atomic force microscopic (AFM) visualization of the morphological alteration. At the UV treatment the time dependence, at the irradiation the change in the dose were the altered factors. The post-treatments of the self-assembled undecenyl phosphonic acid molecular layer resulted in denser nanolayer structures and the consequence was a significantly improved anticorrosion activity. The change in the roughness parameters (maximum height of the profile, roughness average and the root means square roughness) arisen from the AFM measurements proved the influence of post treatments on the layer structure, which could be correlated with the increase in the anticorrosion ability as it is known that with increasing surface roughness the possibility of pitting corrosion increases. The increased anticorrosion activity is due to the formation of a more effective, compact barrier layer between the nanolayer-covered metal surface and the corrosive environment.
\end{abstract}

Received: June 27, 2018. Published: August 6, 2018 doi: $\underline{10.17675 / 2305-6894-2018-7-3-6}$

Keywords: undecenyl phosphonic acid, self assembled molecular layer, contact angle, atomic force microscopy, roughness, corrosion inhibition. 


\section{Introduction}

Metal corrosion causes an important expense in all countries' budget every year. Its efficient control needs a lot of academic and industrial research, especially because the use of the most effective inhibitor - chromate - is banned from the last decade. Among the enormous number of chemicals used as inhibitors in case of different metals, the phosphonic acids - both in dissolved form and in molecular layers - can very effectively inhibit the metal corrosion.

Hetero atoms in organic corrosion inhibitors increase the efficiency in the order of $\mathrm{O}<\mathrm{N}<\mathrm{S}<\mathrm{P}[1-6]$. The adsorption depends on the electron density of the donor atom and of the functional group, which is influenced by the charge, type of electrolyte, and the metal surface. Their efficiency depends on the structure and size of the inhibitor molecule (head group, hydrophobic part etc.), number and type of bonding groups ( $\pi$ or $\sigma$ ) or atoms in the molecule, on the ability to complex formation with the atoms in the metal lattice (substrate's bonding strength). The adsorption between the inhibitor and the metal surface defines the action of the organic inhibitors $[7,8]$. They can form a hydrophobic film from the adsorbed molecules that acts as a protective film on the metal surface. The adsorption of these organic inhibitors depends on the electron density of the donor atom in the functional group. Organic phosphorus compounds as corrosion inhibitors are commonly applied on carbon steel, aluminum, and zinc due to their low toxicity $[9,10]$.

Organic phosphonic acids (which replace the phosphates that increased the eutrophication of natural waters) are very effective in metal corrosion inhibition. They form strong bonds with several metal oxide substrates through formation of stable $\mathrm{Me}-\mathrm{O}-\mathrm{P}$ bonds. The other factor that influences the effectiveness is the molecular structures that have important impact on the anticorrosion efficacy as pointed out by several authors [1113].

The layers developed prior to the corrosive influence could be macroscopic (e.g. paints on metals), and very thin molecular films i.e. nanolayers that also can effectively hinder the corrosion processes [14-17]. The organic nanolayers differ not only in the preparation methods, but also in the films thickness formed on the metal surface.

The anticorrosion efficiency of phosphonic acids depends not only on the anchoring effect of the phosphonic group but also on the hydrophobic molecular part. Shorter carbon chain results in less effective inhibition than a longer one. On the other hand, when functional groups are not only in $\alpha$, but in $\omega$ positions, they also can improve the anticorrosion efficacy $[15,18,19]$.

An important nanocoating of metal surfaces is the surface coverage by ultrathin organic films via self-assembling molecular (SAM) layer [20-22]. This is a simple, spontaneous process applied on a variety of solid surfaces. The self-assembly requires mobile molecules, the layer formation happens in fluid phase when a nanolayer is formed at the solid/liquid interface. The amphiphilic molecules have ionic (or ionizable) head groups and bulky hydrophobic parts. The functional head groups of the amphiphiles 
interact with the substrate anchoring the molecules to the solid material by chemisorption or physisorption that depends on the binding force intensity between the functional group and the metal surface [23]. The other factors that determine the SAM formation are the hydrogen bonds and the van der Waals (lateral) interactions in the monolayer among the hydrophobic molecular parts, mainly among the long carbon chains [24].

The functionalization via SAM layer formation by normal alkyl phosphonic acids could result in strong interactions among the adsorbing molecules and the substrate surfaces [25-27]. Minimum 11-12 carbons in the backbone are required for formation of a closely packed monolayer. It is important to mention that any disturbance in the alkyl chain, especially near to the head group, hinders the formation of a well-defined nanostructure. Some papers summarize the formation of highly ordered molecular assemblies [19, 28, 29].

Several techniques are appropriate for characterization of SAM layer. The surface wettability could be characterized by contact angle values. The AFM, which can operate on air and in liquid, is a proper surface visualizing technique (in 2D and 3D) for characterization of a wide variety of material surfaces achieving resolution down to the nanometer scale [30]. The section analysis gives numerical information about the surface irregularity. The solid surface could also be characterized by different roughness parameters.

The amphiphilic molecule used in these experiments was the undecenyl phosphonic acid.

The self-assembled molecular layer (SAM) of the undecenyl phosphonic acid consists of a $-\mathrm{P}(\mathrm{O})(\mathrm{OH})_{2}$ head group (the geometry of the hydrophilic head group is nearly tetrahedral, can act both as a hydrogen-bond donor via the two $\mathrm{P}-\mathrm{OH}$ groups and a hydrogen-bond acceptor through the $\mathrm{P}=\mathrm{O}$ oxygen) and a hydrophobic side chain. In this case the hydrophobic part is an undecenyl chain with a double bond at the end position that does not allow the formation of a very dense nanolayer.

Our intension was not only to study the most proper condition for development of undecenyl phosphonoic acid SAM layers on carbon steel surface but to try to transform the nanofilm via post-polymerization of the unsaturated bonds in the SAM nanofilm by illumination and irradiation in order to form a polymer net over the metal surface. It could increase the compactness of the surface layer and, parallel, improve the anticorrosion activity. The SAM layer quality, without and with post-treatment, was first extensively investigated by contact angle measurements. Then the metal surfaces were visualized by atomic force microscope. This technique allows the observation of the change in the surface morphology caused by the presence of the nanolayers with or without posttreatment, on one hand, and, on the other hand, to monitor the influence of the electrolytes that can cause either general or pitting corrosion. The surface roughness parameters numerically characterized the change in the nano-coated surfaces submitted to corrosive environment. 


\section{Experimental work}

\subsection{Metal sample preparation}

Carbon steel (composition: C: $2.29 \%$; Fe: $97.71 \%$ ) samples of $10 \times 10 \times 2 \mathrm{~mm}$ in dimension were grinded by silicon carbide emery paper (grit sizes: from 220 to 4000). Afterwards the samples were polished with diamond pastes of different grain sizes (15-9-6-3 $\mu$ ), washed with distilled water, degreased with acetone and dried at atmospheric conditions.

2.2 The amphiphilic molecule was the undecenyl phosphonic acid $\left(\mathrm{CH}=\mathrm{CH}-\left[\mathrm{CH}_{2}\right]_{9}-\right.$ $\mathrm{PO}(\mathrm{OH})_{2}$, product of Specific Polymers, Castries, France: SP-61-003), MW: 234.

\subsection{Self-assembled molecular layer preparation}

The undecenyl phosphonic acid was dissolved in methanol (concentration: $5 \times 10^{-3} \mathrm{M}$ ). The metal samples were immersed into the amphiphile solution for pre-defined time (30 min, $4 \mathrm{~h}, 24 \mathrm{~h}$, and $48 \mathrm{~h}$ ), then the superfluous amphiphile solution was removed by dipping the sample into pure organic solvent. Finally the SAM-coated metal samples with selfassembled molecular layers were left to dry on air.

\subsection{Modification of undecenyl phosphonic acid SAM}

\subsubsection{Post-treatment by UV light illumination}

The SAM layer built from undecenyl phosphonic acid, deposited onto carbon steel was illuminated by UV light $(\lambda=254 \mathrm{~nm})$ for 30 and $60 \mathrm{~min}$.

\subsubsection{Post-treatment by irradiation via ${ }^{60}$ Co gamma source}

Irradiation of undecenyl phosphonic acid SAM layers deposited on carbon steel was performed at room temperature in an SLL-01 type pilot scale facility equipped with ${ }^{60} \mathrm{Co}$ gamma source applying a dose rate of $11.5 \mathrm{kGy} / \mathrm{h}$ (equal to $11.5 \mathrm{~kJ} / \mathrm{kg}$,h). In one case $2 \mathrm{kGy}$, in the other $20 \mathrm{kGy}$ was the absorbed dose.

\subsection{Methods of SAM layer characterization}

\subsubsection{Surface characterization by contact angle values}

Static contact angle values were visualized by a $2 \mu \mathrm{L}$ sessile drop on a home-built device equipped with Hamilton micropipette and CCD camera. The contact angle was determined by geometrical evaluation of the spherical drop [42].

\subsubsection{Atomic force microscopy}

The surface visualization was performed by atomic force microscope (Digital Instruments, NanoScope III). The tip was $\mathrm{Si}_{3} \mathrm{~N}_{4}$ (Veeco, Santa Barbara, CA, USA). The change in the morphology of carbon steel surface with and without nanolayers was imaged in contact 
mode, on air, before and after the corrosive attack. The analysis of the section profile and the roughness of the surfaces allowed numerical evaluation.

\section{Results and discussion}

\subsection{Influence of the SAM layer on the metal surface}

In the first set of experiments the uncoated or by undecenyl phosphonic acid SAM layercoated carbon steel surfaces were investigated. The static contact angle values are summarized in Table 1.

Table 1. Layer formation time and post-treatment dependent static contact angle values measured on carbon steel samples with or without coatings

\begin{tabular}{ccc}
\hline Sample & Treatment & Contact angle [ ${ }^{\circ}$ ] \\
\hline Carbon steel & - & $68 \pm 3^{\circ}$ \\
SAM of undecenyl phosphonic acid (4 h) on carbon steel & - & $86 \pm 3^{\circ}$ \\
SAM of undecenyl phosphonic acid (24 h) on carbon steel & - & $88 \pm 4^{\circ}$ \\
SAM of undecenyl phosphonic acid (48 h) on carbon steel & - & $85 \pm 4^{\circ}$ \\
SAM of undecenyl phosphonic acid (24 h) on carbon steel & $2 \mathrm{kGy}$ & $85 \pm 3^{\circ}$ \\
SAM of undecenyl phosphonic acid (24 h) on carbon steel & $20 \mathrm{kGy}$ & $118 \pm 2^{\circ}$ \\
SAM of undecenyl phosphonic acid (24 h) on carbon steel & $30 \mathrm{~min} \mathrm{UV}$ & $81 \pm 4^{\circ}$ \\
SAM of undecenyl phosphonic acid (24 h) on carbon steel & $60 \mathrm{~min} \mathrm{UV}$ & $102 \pm 3^{\circ}$ \\
\hline
\end{tabular}

As the contact angle values show, an increase in the layer formation time does not cause significant change in the wettability $\left(86^{\circ}, 88^{\circ}\right.$, and $85^{\circ}$ for layers formed at $4 \mathrm{~h}, 24 \mathrm{~h}$, and $48 \mathrm{~h}$ respectively). Already 4 hours was enough to form a nanolayer on the metal surface. In this case the surface is more hydrophobic than the bare metal but the increase in the wettability is not significant. It indicates that the structure of the SAM layer is not very compact; during the water contact angle measurement the water molecules can partly penetrate into the nanolayer.

\subsection{Influence of the layer post-treatments}

\subsubsection{Curing by UV light}

In the case of the carbon steel samples coated by undecenyl phosphonic acid SAM layers in $24 \mathrm{~h}$, shorter illumination time did not really affect the layer hydrophobicity. On the other hand, 60 min UV light illumination resulted in an increased contact angle value (change from $88^{\circ}$ to $102^{\circ}$ ). This indicates that to convert the nanolayer into a more compact form needs longer illumination by UV light, which could be explained by the extended polymerization degree of the double bounds in the surface layer. 


\subsubsection{Influence of irradiation by ${ }^{60}$ Co gamma source}

In one case $2 \mathrm{kGy}$ and in the other $20 \mathrm{kGy}$ was absorbed by the undecenyl phosphonic acid SAM layer deposited onto the carbon steel. In that case when the surface film was handled with $2 \mathrm{kGy}$, the wettability did not change, which is reflected in the similar contact angles: on the uncured SAM layer $88 \pm 4^{\circ}$ and on the cured sample with $2 \mathrm{kGy} 85 \pm 3^{\circ}$ was measured. However, the absorption of $20 \mathrm{kGy}$ increased the contact angle up to $118 \pm 2^{\circ}$ ! This indicates that the irradiation by $2 \mathrm{kGy}$ could only partly polymerize the double bonds in the SAM layer. But the $20 \mathrm{kGy}$ absorption interacted with almost all double bonds at the surface and the SAM layer structure was rearranged. The surface became more compact and the molecular film formed a barrier between the metal surface and the aqueous environment thus decreasing the surface wettability.

\subsection{Surface visualization by atomic force microscopy}

The SAM coated surfaces were investigated by AFM, too. This technique allows the surface visualization in $3 \mathrm{D}$ as well as the numerical characterization of the surface (measure of roughness, section analysis).

\subsubsection{Influence of the SAM layer on the surface morphology and on the anticorrosion behavior}

The AFM images demonstrate the presence of the layer formed in $24 \mathrm{~h}$ without and with curing, and the influence of two electrolytes. First the carbon steel surface is demonstrated without (Figure 1) and with (Figure 2) the nanolayer. On the bare metal surface the presence of an oxide layer (which is fundamental for the SAM layer formation by phosphonic molecules) is unambiguous. The undecenyl phosphonic acid adsorbed onto the metal surface shows a special surface pattern. According to the section analysis the surface smoothness is not influenced by the presence of the nanolayer.
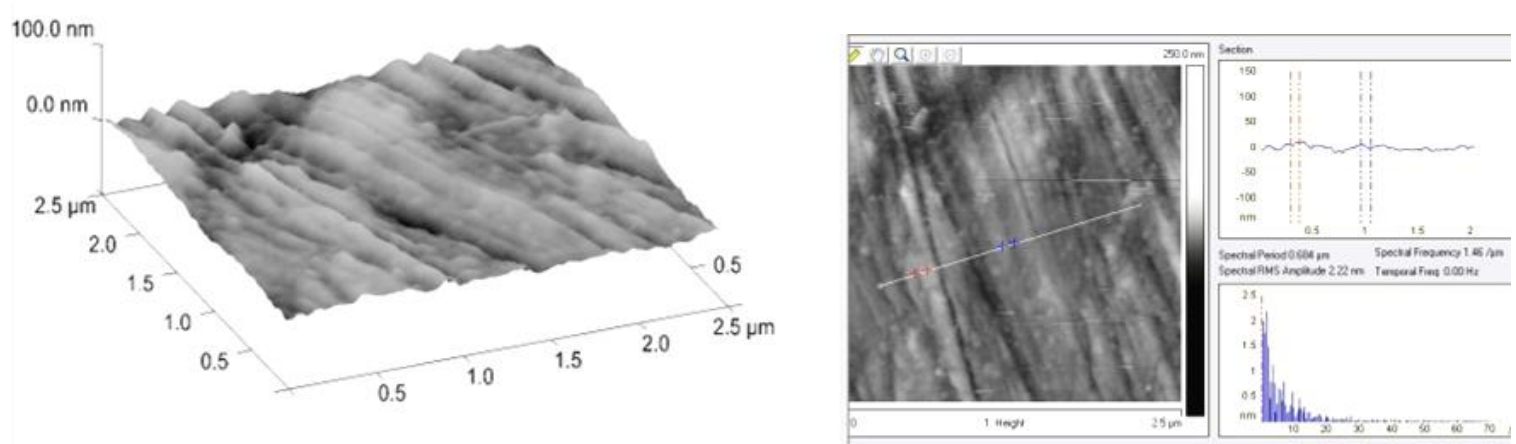

Figure 1. Carbon steel surface visualized by AFM on air, demonstrated by 3D and section. 

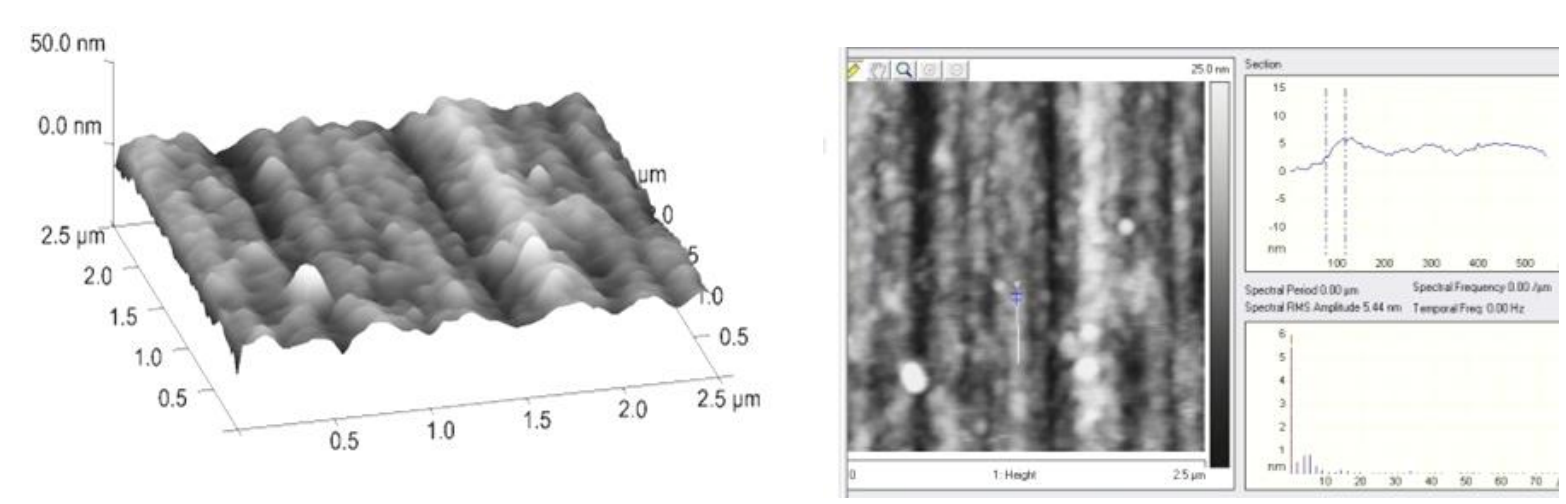

Figure 2. Undecenyl phosphonic acid SAM layer ( $24 \mathrm{~h}$ ) covered carbon steel surface visualized by AFM on air, demonstrated by 3D and section.

On images in Figures 3 and 4 the influence of the irradiation on the undecenyl SAM layers is demonstrated.
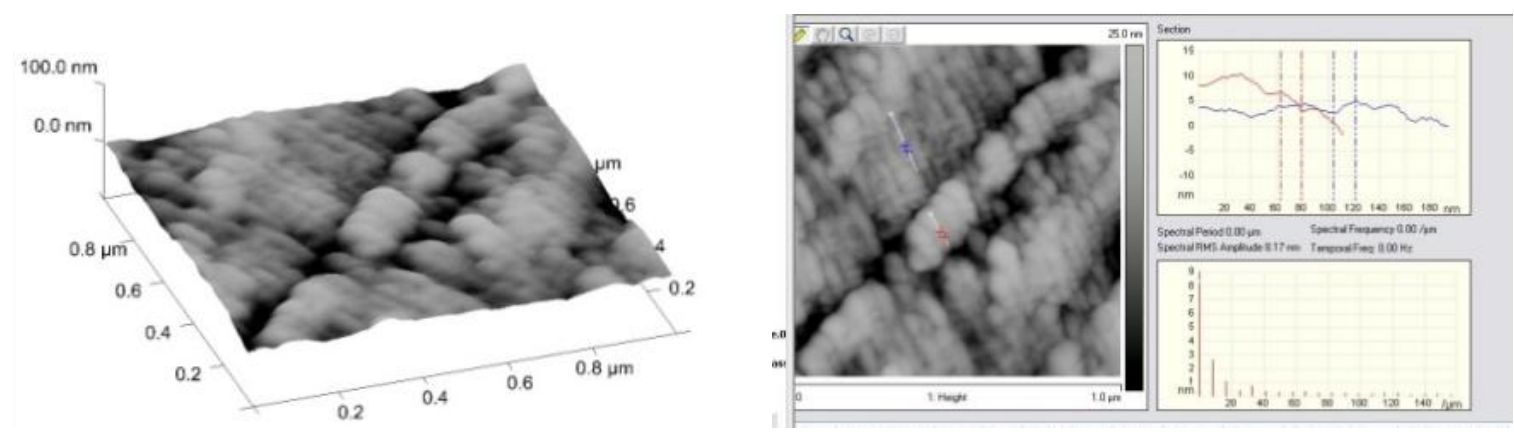

Figure 3. Undecenyl phosphonic acid SAM layer ( $24 \mathrm{~h}$ ) after irradiation: absorption $2 \mathrm{kGy}$ (carbon steel, visualization on air, demonstration by 3D and section).
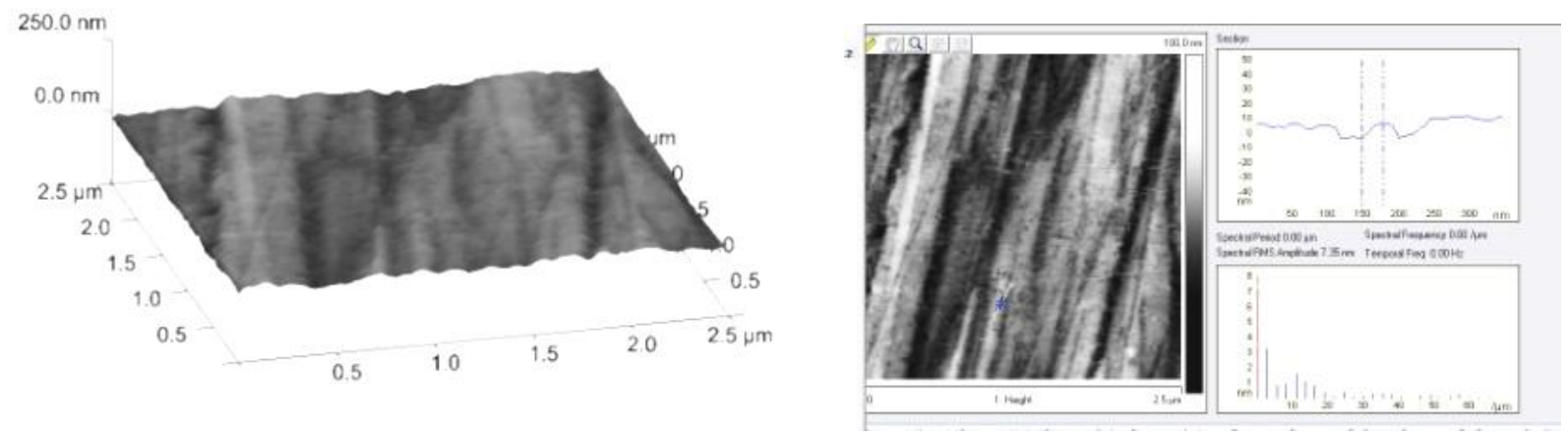

Figure 4. Undecenyl phosphonic acid SAM layer (24 hrs) after irradiation: absorption $20 \mathrm{kGy}$ (carbon steel, visualization on air, demonstration by 3D and section).

The 3D images and the section analysis proved that the amphiphile covers the metal homogenously, and the irradiation left "special signs" on the SAM layers. According to the first attempts in measuring the differences in the surface infrared spectra, it is clear, that in case of the undecenyl amphiphile SAM without irradiation the $\mathrm{CH}_{2}$ groups in the alkenyl chain are visible pointing out the less ordered structure. The $2 \mathrm{kGy}$ absorption did not change the surface morphology significantly. However, the $20 \mathrm{kGy}$ altered the surface, the 
$\mathrm{CH}_{2}$ groups disappeared in the spectrum and - because of the polymerization - the surface character differs from the untreated one drastically. This important change has already appeared in the contact angle values.

The SAM-covered samples were further investigated to study the influence of the SAM layers on the general and pitting corrosion.

\subsubsection{Influence of the SAM layers on pitting corrosion}

The influence of sodium chloride solution onto carbon steel surfaces without any coating and covered by undecenyl phosphonic acid nanolayers was investigated. In a one-hourlong immersion the bare metal corroded, the surface roughened significantly. The undecenyl phosphonic acid SAM layer could partly save the metal surface from pit formation and the roughening of the surface was much less, than of the bare metal (Figure 5). The inhibition is due to the presence of the nanolayer. The efficiency was no $100 \%$, which is the consequence of the not very compact film due to the double bond in the molecule. A small portion of the $\mathrm{Cl}^{-}$ion can penetrate through the nanolayer.

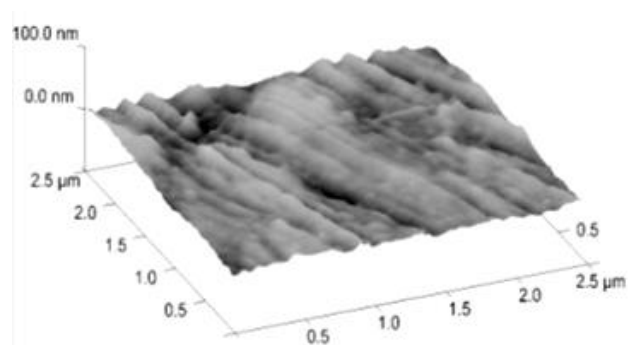

a
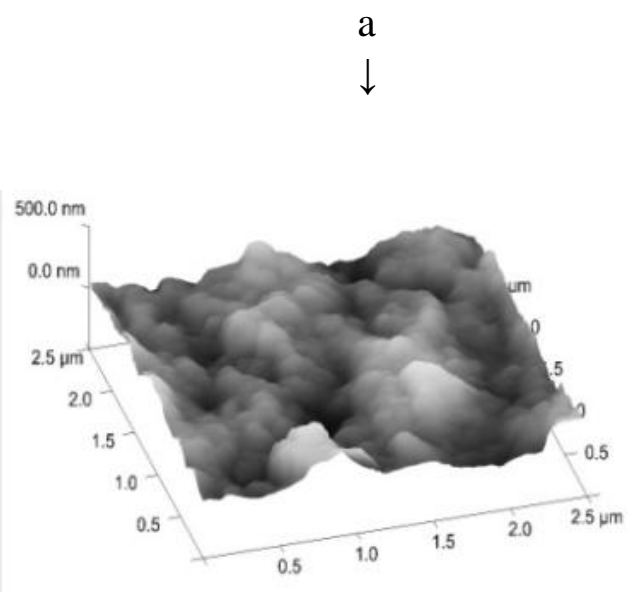

C

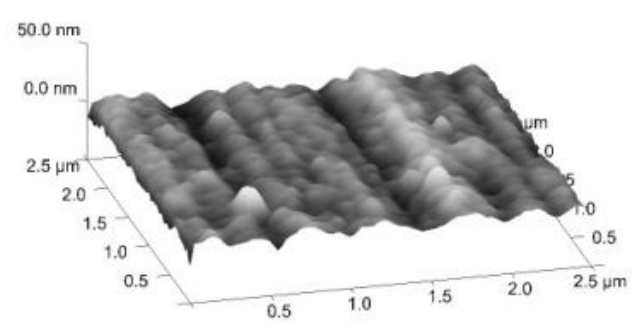

b

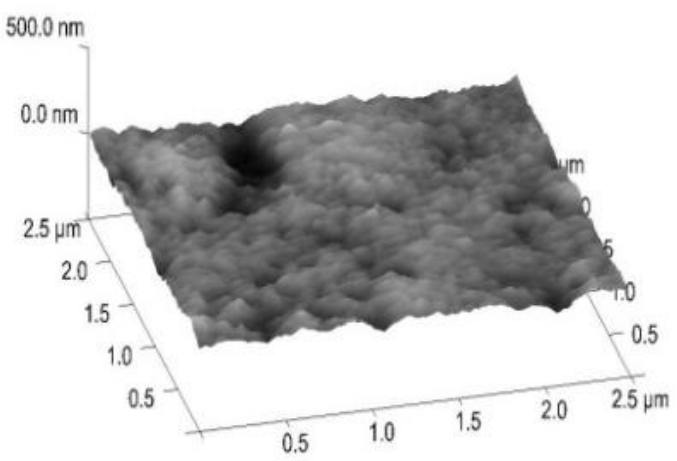

d

Figure 5. Influence of sodium chloride solution on carbon steel: "a" and "c": bare metal surface before and after immersion in chloride solution for $1 \mathrm{~h}$; " $\mathrm{b}$ " and $\mathrm{d}$ ": undecenyl phosphonic acid SAM layer covered carbon steel surface and its immersion into chloride solution for $1 \mathrm{~h}$. 


\subsubsection{Undecenyl phosphonic acid SAM layers against the general corrosion}

The influence of undecenyl phosphonic acid SAM layers on the general corrosion, investigated in aerated sodium perchlorate solution after one hour immersion, was followed by AFM images. Contrary to the influence of sodium chloride, in perchlorate with oxygen, the nanolayer covered carbon steel surface remained smooth proving the effective inhibition of the SAM film.

\subsubsection{Influence of the SAM layer post-treatment on the anticorrosion efficacy}

The irradiation of the SAM layer resulted in alteration not only in the surface morphology but in the anticorrosion activity, too.

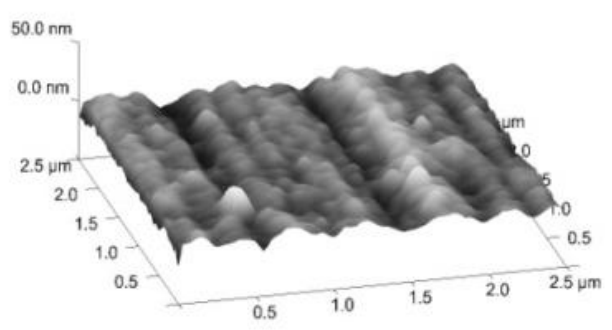

carbon seel with UP24h SAM
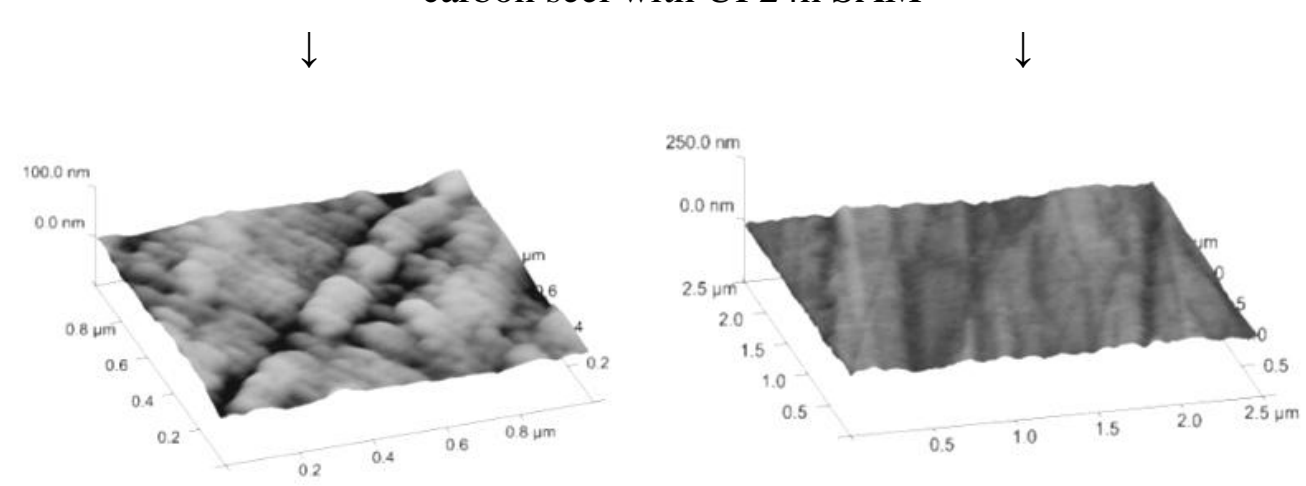

Carbon steel UP 24 h SAM +2 kG

Carbon steel UP 24 h SAM + $20 \mathrm{kG}$
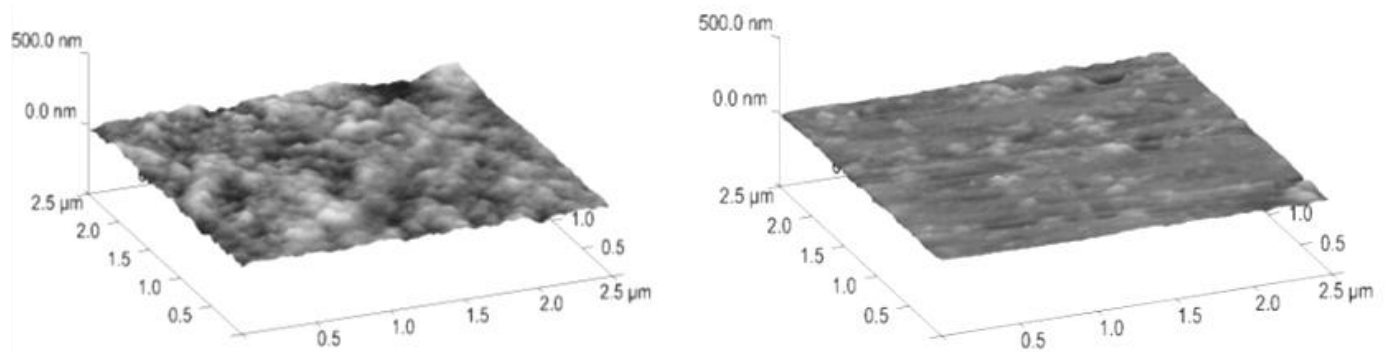

Carbon steel UP $24 \mathrm{~h}+2 \mathrm{kG}+1 \mathrm{~h} \mathrm{NaCl}$ Carbon steel UP $24 \mathrm{~h}+20 \mathrm{kG}+1 \mathrm{~h} \mathrm{NaCl}$

Figure 6. Influence of the surface modification by irradiation on the anticorrosion activity (UP $24 \mathrm{~h}$ : undecenyl phosphonic acid SAM layer developed in $24 \mathrm{~h}$ ). 
Figure 6 demonstrates the increased anticorrosion effect caused by the irradiated nanolayer coating on the carbon steel surfaces. It is clear that even the $2 \mathrm{kGy}$ absorption made the nanolayer more resistant against the pitting corrosion, i.e. the layer compactness increased. The $20 \mathrm{kGy}$ irradiation modified not only the layer surface but, because of the formation of a net-like structure, the pitting corrosion inhibiting activity increased extremely, the surface is very smooth and does not have pits.

3.3.5 Surface characterization by roughness parameters

The surface roughness is defined as a vertical deviation of a real surface from its smooth form. The roughness plays an important role in various processes. The surface roughness cannot be accurately characterized by using a single parameter. Instead, a set of roughness parameters is defined and used. To characterize the surface profiles 2D parameters are used and marked with the letter ' $R$ '.

Roughness parameters calculated by the AFM software were used to characterize numerically the influence of the corrosive environment.

Three different roughness parameters were taken into consideration:

$i$. Maximum height of the profile $\left(R_{\max }\right)$ : the vertical distance between the deepest valley and highest peak around the surface profile; this is the most significant parameter.

ii. Roughness average $\left(R_{\mathrm{a}}\right)$ : the average roughness is the mean absolute profile; it does not make any distinction between valleys and peaks.

iii. Root means square roughness $\left(R_{\mathrm{q}}\right)$ : this is a statistical measure, which is similar to the roughness average.

It is well known, that with increasing surface roughness the possibility of pitting corrosion increases, with other words a smoother surface is less corroded than a rougher one because on a smoother surface the number of the defect places is reduced. Two different processes contribute to the pitting corrosion on smooth and rougher surface:

1. The pit formation ability is contributed to the presence of surface defects, which are more numerous on rough surface. On smooth surface the number of the defect places is reduced because of passivation.

2. The diffusion of corrosion causing species (e.g. chloride ions) is affected by the surface roughness.

When the aggressive species are in contact with a surface and the diffusion of the corrosion products are limited, the repassivation of the metal is reduced and that allows growing of a pit. The deep grooves trap the aggressive species, and the corrosion product cannot diffuse out of the groove; this increases the growth of the pit. On the other hand, when corrosion products can quickly diffuse out, no accumulation of the aggressive species can happen, the metal surface could be repassivated. In case of repassivation or stable oxide layer formation pit nucleation and growth is reduced. 
The visualization of a surface by atomic force microscope permits the calculation of the surface roughness at nanoscale. It far exceeds the resolution got by other (e.g. optical) methods. The understanding of the nanoscale roughness is becoming more and more important.

The measured surface roughness depends on the spatial and vertical resolution of an instrument. A real surface exhibits roughness on many length scales. Two important factors affect the resolution of roughness values measured at the metal surface: the vertical resolution, which is limited by the noise, and the spatial resolution limited by the tip radius.

The atomic force microscope was used to determine the roughness parameters, which are summarized in Tables 2 and 3.

Table 2. Roughness parameters of carbon steel surfaces covered by undecenyl phosphonic acid SAM layer (formed in $24 \mathrm{~h}$ ) with and without irradiation treatment.

\begin{tabular}{ccccc}
\hline Sample & Treatment & $\boldsymbol{R}_{\mathbf{q}}[\mathbf{n m}]$ & $\boldsymbol{R}_{\mathbf{a}}[\mathbf{n m}]$ & $\boldsymbol{R}_{\mathbf{m a x}}[\mathbf{n m}]$ \\
\hline carbon steel & - & 5.3 & 4.2 & 53.1 \\
carbon steel with undecenyl SAM layer & - & 4.9 & 3.7 & 40.4 \\
carbon steel with undecenyl SAM layer & $2 \mathrm{kGy}$ & 6.6 & 5.0 & 73.0 \\
carbon steel with undecenyl SAM layer & $20 \mathrm{kGy}$ & 8.8 & 7.2 & 67.6 \\
\hline
\end{tabular}

Analyzing the roughness parameters summarized in Table 2, the average roughness profile $\left(R_{\mathrm{a}}\right)$ values measured on the bare and the nanolayer covered carbon steel did not show significant differences, but after irradiation, the $R_{\mathrm{a}}$ values increase a little. The root means square roughness $\left(R_{\mathrm{q}}\right)$ values (which are more sensitive to the valleys and peaks than the average roughness) show similar trend than the $R_{\mathrm{a}}$ values. Additionally, the $R_{\max }$ parameters followed the same tendency.

On the other hand, when the metal sample without coating was dipped into chloride solution, all three roughness values increased drastically; the $R_{\mathrm{q}}$ and $R_{\mathrm{a}}$ values about twenty times, the $R_{\max }$ around twelve times are higher (Table 3). The situation is different in the presence of the SAM layer. After immersion of SAM covered metal into sodium chloride solution, the $R_{\mathrm{a}}$ and $R_{\mathrm{q}}$ roughness parameters are less than ten times, the $R_{\max }$ around ten times higher than without the chloride ions. The influence of the irradiation on the layer structure makes the appearance striking; in the case of $20 \mathrm{kGy}$ absorption, all three roughness parameters are much less than without the influence of the chloride solution. Even the $2 \mathrm{kGy}$ irradiation could improve the roughness values and, in parallel, the anticorrosion efficiency.

The roughness parameters observed on the AFM images show the importance of this phosphonic acid amphiphile SAM layers in the inhibition of pitting corrosion. 
Table 3. Effect of $\mathrm{NaCl}$ on roughness parameters of carbon steel surfaces covered with undecenyl phosphonic acid SAM layer (formed in 24h).

\begin{tabular}{ccccc}
\hline Sample & Treatment & $\boldsymbol{R}_{\mathbf{q}}(\mathbf{n m})$ & $\boldsymbol{R}_{\mathbf{a}}(\mathbf{n m})$ & $\boldsymbol{R}_{\mathbf{m a x}}(\mathbf{n m})$ \\
\hline carbon steel & $1 \mathrm{~h} \mathrm{NaCl}$ & 103 & 84.1 & 644 \\
carbon steel with undecenyl SAM layer & $1 \mathrm{~h} \mathrm{NaCl}$ & 38.5 & 29.5 & 472 \\
carbon steel with undecenyl SAM layer & $2 \mathrm{kGy}+1 \mathrm{~h} \mathrm{NaCl}$ & 14.6 & 11.4 & 144 \\
carbon steel with undecenyl SAM layer & $20 \mathrm{kGy}+1 \mathrm{~h} \mathrm{NaCl}$ & 6.7 & 4.9 & 94 \\
\hline
\end{tabular}

\section{Conclusion}

1. Based on the observation of the contact angle values and the atomic force microscopic images the undecenyl phosphonic acid SAM layer without post-treatment can decrease the pitting corrosion but the general corrosion more efficiently.

2. A longer (60 min) UV illumination of the SAM layer can interact with the double bonds of the undecenyl alkenyl chain and the polymerization makes the nanofilm more compact as the increased contact angle value shows.

3. When the undecenyl phosphonic acid SAM layers were irradiated by gamma ray, the influence on the morphology and on the anticorrosion activity is dose-dependent: smaller absorption of the gamma ray is not enough to a complete polymerization of the double bonds in the nanofilm and, parallel, the increase in the anticorrosion efficiency is smaller. But the parameters both in the wettability and the anticorrosion activity are much better when the surface irradiation is more active, i.e. when the surface absorbed $20 \mathrm{kGy}$. According to the preliminary FTIR measurements, the peak of the $-\mathrm{CH}_{2}-$ groups almost disappears after the $20 \mathrm{kGy}$ irradiation proving the polymerization of the double bonds in the SAM layer.

4. The tendency in the change of all three roughness parameters was similar: the presence of the SAM layer on the carbon steel decreases the $R_{\mathrm{q}}, R_{\mathrm{a}}$ and $R_{\max }$ values. The same was observed when chloride ions attacked the uncoated and coated metal surfaces. Dramatic decrease in the roughness values were measured when the undecenyl phosphonic acid SAM layers were first irradiated and then immersed into the sodium chloride solution. Even in the case of the $2 \mathrm{kGy}$ absorption, the roughness parameters decrease (pointing out the increased compactness of the nanolayer), and at $20 \mathrm{kGy}$ the improvement in the anticorrosion activity is very high.

\section{Acknowledgement}

The authors render their thanks to Zoltán Papp (Institute of Isotopes Co. Ltd., Budapest, Hungary) for irradiation of the SAM layers. 


\section{References}

1. G. Trabanelli, Corrosion, 1991, 47, no. 6, 410-419.

2. Yu.I. Kuznetsov, Corrosion, 1995, 853-859.

3. Yu.I. Kuznetsov, A.A. Chirkunov, A.S. Gorbachev and N.P. Andreeva, Int. J. Corros. Scale Inhib., 2017, 6, no. 3, 318-332. doi: 10.17675/2305-6894-2017-6-3-7

4. Yu.I. Kuznetsov, Int. J. Corros. Scale Inhib., 2017, 6, no. 4, 384-427. doi: $\underline{10.17675 / 2305-6894-2017-6-4-3}$

5. M.O. Abdulazeez, A.K. Oyebamiji and B. Semire, Int. J. Corros. Scale Inhib., 2016, 5, no. 3, 248-262. doi: $\underline{10.17675 / 2305-6894-2016-5-3-5}$

6. P.B. Raja, M. Ismail, S. Ghoreishiamiri, J. Mirza, M.C. Ismail, S. Kakooei and A.A. Rahim, Chem. Eng. Commun., 2016, 203, no. 9, 1145-1156.

7. H. Amar, T. Braisaz, D. Villemin and B. Moreau, Mater. Chem. Phys., 2008, 110, 1-6.

8. R.S. Abdel Hameed, Abd-Alhakeem, H. Abu-Nawwasb and H.A. Shehata, Adv. Appl. Sci. Res., 2013, 4, 126-129.

9. X.H. To, N. Pebere, N. Pelaprat, B. Boutevin and Y. Hervaud, Corros. Sci., 1997, 39, 1925-1934.

10. A. Paszternák, S. Stichleutner, I. Felhősi, Z. Keresztes, F. Nagy, E. Kuzmann, A. Vértes, Z. Homonnay, G. Pető and E. Kálmán, Electrochim. Acta, 2007, 53, 337345.

11. P. Atkins and J. de Paula, Physical Chemistry for the Life Sciences, Oxford University Press, 2006, 209-225.

12. J. Telegdi, E. Kálmán and F.H. Kármán, Corros. Sci., 1992, 33, 1099-1103.

13. J. Telegdi, Int. J. Corros. Scale Inhib., 2016, 5, no. 2, 183-189. doi: 10.17675/23056894-2016-5-2-7

14. A. Alagta, I. Felhősi, I. Bertóti and E. Kálmán, Corros. Sci., 2008, 50, no. 6, 16441649.

15. I. Felhősi and E. Kálmán, Corros. Sci., 2005, 47, no. 3, 695-708.

16. D.L. Allara and R.G. Nuzzo, Langmuir, 1985, 1, 45-52.

17. L. Allara and R.G. Nuzzo, Langmuir, 1985, 1, 52-66.

18. J. Bockris, D. Drazic and A. Despuc, Electrochim. Acta, 1961, 4, 325.

19. I. Felhősi, J. Telegdi, G. Pálinkás, E. Kálmán, Electrochim. Acta, 2002, 47, 23352340.

20. H. Amar, J. Benzakour, A. Derja, D. Villemin and B. Moreau, J. Electroanal. Chem., 2003, 558, 131.

21. E. Jaehne, S. Oberoi and H.-J. P. Adler, Progr. Org. Coat., 2008, 61, 211.

22. Yu. I. Kuznetsov, Bull. Electrochim. Acta, 1990, 6, 571.

23. P. Lobeer and W. Lorenz, Electrochim. Acta, 1980, 25, 375.

24. J.M. Costa and A.D. Mercer, Progress in the Understanding and Prevention of Corrosion, Institute of Materials, London, 1993, 1, 844. 
25. Min Soo Lim, K.J. Smiley and E.S. Gawalt, Amphiphiles: Molecular Assembly and Applications, Chapter 1, pp. 1-22, ACS Symposium Series, 2011, 1070, 193-204. doi: 10.1021/bk-2011-1070.ch001, ISBN13: 9780841226500

26. I. Doudevski and D.K. Schwartz, Langmuir, 2000, 16, 9381-9384.

27. H.-Y. Nie, D.J. Miller, J.T. Francis, M.J. Walzak and N.S. McIntyre, Langmuir, 2005, 21, 2773-2778.

28. Y.I. Kuznetsov, Organic inhibitors of corrosion of metals, Ed. J.G.N. Thomas, Plenum Press, New York, London, 1996

29. H.N. Shubha, T.V. Venkatesha, K. Vathsala, M.K. Pavitra and M.K. Punith Kumar, ACS Appl. Mater. Interfaces, 2013, 5, no. 21, 10738-10744.

30. Zs. Keresztes, T. Rigó, J. Telegdi and E. Kálmán, Appl. Phys., A, 2001, 72, S113S116.

31. H.Y. Erbil, Adv. Colloid Interface Sci., 2012, 170, no. 1-2, 67-86. 